\title{
DIE WYSGERIGE KONSEPSIE VAN THOMAS VAN AQUNNO
}

\section{DEEL I: SY ONTOLOGIE}

Die arbeid van Thomas kan met dié van 'n elektriese transformator vergelyk word. $\mathrm{Hy}$ vang die strome van die verlede op en bring die worsteling en besinning van vele eeue in 'n sekere sin tot 'n afsluiting en 'n definitiewe resultaat. Die gedagtestrominge van die verlede word deur hom saamgebundel en getransformeer tot 'n magtige konsepsie: so kragtig dat die impulse daarvan tot op die hede waarneembaar is. Die weerklanke van sy gedagte klink deur tot vandag toe - nie net binne die Rooms-Katolieke Kerk, waar sy filosofie tot amptelike leer verklaar is nie, maar ook daarbuite.

\section{METODOLOGIESE PROBLEEM: WAS THOMAS 'N TEO- LOOG OF FILOSOOF?}

Dit is ' $n$ ou strydpunt of Thomas ' $n$ teoloog of filosoof, of in die eerste plek teoloog of primêr filosoof was.

Dit is uit sy werke duidelik dat Thomas nie bloot teoloog of suiwer filosoof is nie. Wat egter die presiese verhouding tussen Wysbegeerte en Teologie in sy werke is, is die probleem. Het Thomas alleen die Filosofie gebruik as 'n middel ter verwerkliking van sy Teologie of het hy moontlik die gegewens van die Christelike geloof as voorwendsel gebruik om te kan filosofeer?

Uit die inhoud van Thomas se werke, maar ook na aanleiding van wat hyself oor die verhouding tussen Teologie en Wysbegeerte sê (waaroor later gehandel word) kan met veiligheid aangeneem word dat Thomas self in die eerste plek teoloog wou wees. Hy wou as teoloog in sy Teologie (sacra doctrina) die Woord van God interpreteer, sistematiseer, begryp en verduidelik. Die studie van die Wysbegeerte, waarin dit vir hom om die kosmiese dinge gaan, word deur hom nie ter wille van sigself onderneem nie maar gesubordineer aan die primêre teologiese doelstelling.

Hierdie stand van sake maak dit natuurlik nie so eenvoudig om die wysgerige voorveronderstellings van Thomas se denke op te spoor nie. Die meeste tradisionele Thomiste (geinspireer deur die ideaal van 'n philosophia perennis) soos byvoorbeeld Garrigou-Lagrange en Maritain, het van die veronder- 
stelling uitgegaan dat dit moontlik is om uit Thomas se geskrifte ' $n$ volledige, suiwer rasionele Thomistiese filosofie te distilleer. Selfs iemand soos Gilson, wat groter klem op die invloed van die Christendom op Thomas se denke gelê het, glo dat ' $n$ volledige filosofiese stelsel $-a$ al is dit dan 'n "Christelike" filosofie - by Thomas te vind sou wees. Die groot vraag is natuurlik of dit wel moontlik is om uit Thomas se gedagtewêreld die filosofiese inslag te isoleer en op dié wyse tog nog 'n selfstandige, lewende geheel as eindresultaat te bereik. Is nie veel eerder 'n baie kunsmatige produk die eindresultaat nie?

Die bedoeling van hierdie ondersoek na die ontologiese agtergronde in Thomas se Summa Contra Gentiles is nie om 'n volledige en sluitende filosofiese stelsel uit die oorwegend teologiese konteks te distilleer nie. Aangesien elke wetenskap egter (ook in die gevalle waar dit nie erken word nie) op wysgerige voorveronderstellings gebou is, kan dit ook in die geval van die Summa Contra Gentiles nagespeur word veral waar Thomas so duidelik erken dat hy in sy Teologie van die Wysbegeerte gebruik maak en gesien die feit dat sy Summa Contra Gentiles meestel as sy filosofiese hoofwerk (teenoor die Summa Theologiae as sy teologiese hoofwerk) beskou word.

Uit wat sover in verband met die verhouding tussen Teologie (volgens hom wetenskaplike bestudering van die Bybel) en Wysbegeerte (volgens hom wetenskaplike bestudering van die kosmos as geheel) by Thomas gestel is, mag nie die konklusie getrek word dat sy Teologie suiwer Skrifmatig is en dat die Wysbegeerte wat daaruit gedistilleer sal word uit en uit heidens is nie. Die eenheid wat Thomas, as dié verteenwoordiger uit die bloeiperiode van die sintesedenke, tussen Bybelse en Griekse denke bewerk het, is veel intiemer en geld vir sowel Wysbegeerte as Teologie. Binne sy teologiese denke het daar as gevolg van die sintese-mentaliteit talle pagane elemente ingesluip en die wysgerige denkbeelde wat hy van byvoorbeeld Aristoteles oorgeneem het, het ook nie onaangeraak gebly deur die Bybelse openbaring nie.

Thomas se denke mag nie as Bybelse denke bestempel word bloot as gevolg van die feit dat die inhoud van sy denke meestal Bybelse gegewens is nie. 
Thomas se bedoeling was wel om Bybels en Christelik in sy Teologie te dink, maar sy denke sou nie as radikaal-Bybels of Skrifmatig nie, dog eerder as Christelike sintesedenke getipeer kon word.

\section{ONTOLOGIESE VOORVERONDERSTELLINGS.}

Die Summa Contra Gentiles verteenwoordig ' $n$ bepaalde fase in Thomas se filosofiese ontwikkelingsgang. Wat sekere sake betref, het hy dwarsdeur sy lewe in al sy geskrifte dieselfde standpunt gehuldig. Hy het byvoorbeeld steeds sinteties, louter-kosmologies, dualisties en parsieel-universalisties (sonder makro-mikrokosmos-tema) gedink. 'n Noukeurige studie van sy werke toon egter aan dat daar twee hoofperiodes (elk met twee verdere onderverdelings) in sy denkontwikkeling onderskei moet word.

Van belang is hier alleen sy wysgerige konsepsie soos wat dit in die Summa Contra Gentiles aangetref word. Dit val binne. die tweede hooffase van sy wysgerige ontwikkelingsgang waarin die invloed van Aristoteles duideliker na vore kom. Teenoor die eerste hooffase, wat as die Platoniserend-monarchianistiese periode aangedui kan word (tot ongeveer 1259), word hieride periode $(1260-1274)$ as dié van Aristotelesinterpretasie gekarakteriseer waarin Thomas die subsistensieteorie aanvaar. Aanvanklik (1260 - 1265) huldig hy 'n Platoniserende vorm van die subsistensieteorie, maar as die invloed van die Aristoteliserende denke sterker word, gaan hy tot 'n nie-Platoniserende subsistensieteorie oor wat karakteristiek van die finale periode van sy denkarbeid $(1265-1274)$ is. Die Summa Contra Gentiles verteenwoordig die tweede laaste (Platoniserende) fase en die Summa Theologiae die laaste (nie-Platoniserende) fase in Thomas se wysgerige ontwikkelingsgang.

\subsection{LOUTER-KOSMOLOGIESE DENKE}

As antwoord op die vraag vanwaar die aardsgeskape werklikheid kom, gebruik Thomas nie die mite nie, sodat hy nie mitologiserend dink nie. Hy stel die wording van die kosmos ook nie primêr nie, sodat hy ook nie 'n kosmogono-kosmologiese visie huldig nie. Hy probeer nie die ontstaan van die dinge wysgerig verklaar nie maar gaan van die Skrifwaarheid van die skepping uit waarvan hy 'n Aristotelies-gekleurde filosofiese interpretasie bied. Thomas handel volkome tereg 
as hy alleen oor die bestaande dinge wil filosofeer en nie op die wordingsvraag wil ingaan nie.

Sy louter-kosmologiese denke het egter ook skadukante. Hy vra wel na die lig van die Skrif vir die werklikheid, maar as gevolg van sy louter-kosmologiese uitgangspunt word die lig van die Skrif geweldig vereng.

Die woord van God openbaar dat God daar is, dat Hy geskape het en dat Hy sy wette vir die skepping gestel het. Volgens 'n Skrifmatige wysgerige Ontologie moet daar dus tussen die samehangende verskeidenheid van God, wet en kosmos onderskei word. Thomas se Ontologie word as gevolg van sy louter-kosmologiese denke (skepping, sondeval en verlossing) egter tet 'n Kosmologie vereng. Aangesien God en wet egter realiteite is wat nie geloën kan word nie, is Thomas verplig om hulle (soos weldra sal blyk) op een of ander manier onder sy Kosmologie tuis te bring.

Die lig wat die Skrif volgens Thomas op die aardsgeskape (kosmiese) werklikheid werp, kan in drie woorde, naamlik "skepping, sondeval en verlossing" saamgevat word waarvan skepping en verlossing volgens hom die belangrikste momente is.

\subsection{DUALISME}

Aangesien Thomas se louter-kosmologiese denke inhou dat hy eintlik net een syn (in plaas van drie), naamlik dié van die kosmos erken, is die vraag wat hy dan met God gemaak het. Die antwoord hierop lê in sy dualisme opgelsuit. Volgens die monisme is die eenheid primêr en die veelheid (wat uit die eenheid gegroei het) sekondêr. Die dualistiese denkers se antwoord op die vraag hoe die werklikheid oorspronklik daar uitgesien het, is egter dat die veelheid (gewoonlik tot'n tweeheid reduseerbaar) primêr is.

Volgens Thomas se dualistiese visie moet binne die een syn tussen ' $n$ hoëre, transendente en 'n laere, nie-transendente "deel" onderskei word. Gedoop met Christelike terme dui Thomas die twee komponente in hierdie Griekse (en dus heidense) dualisme nie as die transendente en die nie-transendente aan nie maar as God (Skepper) en skepping. Bloot op die spraakgebruik gelet, wil dit dus voorkom asof Thomas heel Skrifmatig dink deur Skepper en skepping te onderskei. 
Op die keper beskou huldig hy egter 'n onskrifmatige visie, aangesien hy God en kosmos in één syn (as die transendente en nie-transendente deel daarvan) saamgevat het. Die implikasies daarvan is dat die radikale verskil tussen God en die skepping in sy denke nie werklik erken kan word nie.

In hierdie God-kosmos-filosofie moet Thomas nou die verhouding tussen God en kosmos bepaal. Is God nou heeltemal transendent aan die kosmos sodat $\mathrm{Hy}$ niks daarmee te make het nie? Die Bybelse openbaring van God se bemoeienis met sy skepping dwing Thomas om die idee te verwerp. Hy wil die alomteenwoordigheid van God aanvaar. Aangesien hy God (onder invloed van die dualisme) egter ruimtelik reeds (as die transendente) geplaas het, kan hy God se alomteenwoordigheid nie meer Skrifmatig korrek sien nie maar alleen in die sin van immanensie, dit wil sê, só dat God deel van die skepping word. Wie egter die radikale onderskeid tussen God en skepping erken, en dus nie ruimtelike maatstawwe (iets wat alleen vir die skepping geld) op God toepas nie, hoef nie die Bybelse leer van God se teenwoordigheid só te verstaan dat God deel van die skepping word nie.

Die verhouding tussen God en kosmos mag egter nie volgens die skema van deel-geheel benader word nie. Terselfdertyd is die toepassing van die skema van ooreenkoms en verskil ten opsigte van die God-kosmosverhouding onskriftuurlik Soos verderaan sal blyk, is dit egter presies wat Thomas doen. Veral uit sy leer van die analogia entis sal blyk hoe die idee van ooreenkoms in verskil (of verskil in ooreenkoms) op die verhouding God-kosmos van toepassing gemaak word.

Voordat daaraan aandag gegee kan word, moet egter nagegaan word wat Thomas met die wet binne sy louter-kosmologiese, dualistiese konsepsie gemaak het. Hoewel hy dit nie meer Skrifmatig korrek kon sien nie (aangesien hy net eén dualisties gekonsipieerde syn erken) het hy die wet nie geignoreer nie. Inteendeel, dit speel ' $n$ uiters belangrike rol in sy hele konsepsie.

\subsection{PARSIELE UNIVERSALISME SONDER MAKRO- MIKROKOSMOSTEMA}

Teenoor die uiterstes van die universalimse en die individualisme, wat respektiewelik die universele en die individuele aspekte van die kosmiese werklikheid primêr stel, huldig 
Thomas 'n meer gematigde standpunt waarin gepoog word om sowel die universele as die individuele tot hul reg te laat kom. Volgens hom is die universele wel nog die belangrikste (vandaar die tipering van sy konsepsie as Parsiële Universalisme) maar die individuele kry ook 'n plek. Hy sien egter nie die universele en die individuele as apart bestaandes, langs mekaar soos die parsiële universaliste wat die makro-mikrokosmos-tema aanvaar het nie. Volgens hom kom die universele en die individuele (as die hoëre en laere komponente) in een en dieselfde ding voor. Dit is sy bekende vorm-materieleer of hulemorfisme wat hy van Aristoteles oorneem. Die universele is dieselfde as die hoëre vorm en die individuele as die laere materie. Elke geskape ding bestaan dus uit materie en vorm.

Thomas se standpunt ten opsigte van die verhouding tussen die universele en die individuele bring ons ook by sy wetsontologie aangesien die wet (ten onregte) reeds vroeg in die Westerse denke met die universele vereenselwig is.

Sy worstelinge rondom die wet het uiteindelik op die idee van universalia ante rem, in re en post rem uitgeloop: die wet bestaan vóór die (kosmiese) dinge in God, word deur God in die dinge geskape en kan deur die menslike rede weer uit die dinge geabstraheer word. Dit is in 'n neutedop ook Thomas se wetsontologie wat vervolgens breedvoeriger ondersoek sal word.

\subsection{WETSONTOLOGIE}

Thomas plaas die wet dus ook binne die een syn wat in 'n transendente (God) en nie-transendente (skepping) verdeel word. Die wet word met sowel God as die skepsel verwar.

Volgens Thomas is God suiwer vorm of essensie (wet). By die skepsele is daar verskil tussen vorm en materie, essensie en eksistensie, maar by God val dit saam. God is sy essentia, quidditas of natura. God se wese word verder nou met sy intellek verbind: wese en intellek is dieselfde.

Die essensies van die kosmiese dinge bestaan dan ook in mente Dei en word deur God in die dinge ingeskape. God se wese is die exemplar van alle dinge, want God bevat in sy wese die ideale of modelvorme (wette) van die verskillende skepsele. Ons moet dit so voorstel dat God, behalwe sy eiesoortige wet, in Hom ook wette (eksemplare) vir elke partikuliere ding 
bevat. Die eksemplare is dus nie identies met die essensie van God nie maar lê in die goddelike essensie opgesluit. Skematies voorgestel: Van twee konsentriese sirkels dui die buitenste een God se eksistensie en die binnenste een sy essensie of wese aan. Eintlik lê Thomas soveel klem op die essensie van God dat hy beweer dat die essensie en eksistensie van God saamval. (Die konsekwensies hiervan in die lig van 'n Skrifmatige Filosofie is dat God sowel versubjektiveer as verwettiseer word, omdat $\mathrm{Hy}$ as subjek sowel as wet gesien word.) Tussen die twee konsentriese sirkels lê die exemplares waarvolgens God die dinge skep. Hierdie argetipiese voorbeelde vir die geskape dinge is dus nie identies met die wese of essensie van God nie maar slegs analoog daaraan.

Volgens hierdie vorme ante rem in God word die vorme of wesens in rebus dit wil sê in die aardse dinge (wat dan uit vorm en materie bestaan) geskape. Thomas gebruik graag die beeld van die kunstenaar en die kunsproduk om te verduidelik hoe die dinge deur God geskep word. Volgens die plan in sy denke skep die kunstenaar en so ook God volgens die eksemplare in sy intellek. Die vorme, wesens of wette in die geskape dinge is volgens Thomas se subsistensieteorie subsisterende vorme, aangesien hulle God in die skepping assisteer of help. Deur abstaksie kan hierdie vorme weer van hulle materiële binding losgemaak word en post rem in die kennende gees van die mens verskyn.

Meer van die kant van die skepsele besien, heet die eksemplare gelykenisse, afbeeldings of nabootsings (similitudines). God deel sy natuur (wese, wet) deur middel van die similitudines aan die dinge mee. Hierdie similitudo of gelykenis met God lê in die vorm of wet in die ding. Die skepsele lyk op God volgens hul vorme.

Thomas stel duidelik dat, aangesien die skepsel sy gelykenis met God aan God te danke het (die vorm wat God daarin skep), alleen gesê mag word dat die skepsel die gelykenis van God vertoon en nie die omgekeerde, naamlik dat God die gelykenis van die skepsel dra nie. Hoe sterk Thomas egter die gelykenis sien, blyk ook daaruit dat hy sê die dinge kopieer, imiteer of representeer God met betrekking tot hulle vorme. In die lig van die logosspekulasie wat by die Apologete en in 'n ander vorm by Augustinus aangetref is, is dit besonder interessant dat Thomas van die similitudines ook as rationes 
spreek. By Augustinus is die leer van die rationes seminales, causales of aeternae gevind waarmee hy in wese dieselfde aangedui het as die logoi spermatikoi van die Apologete wat op op hulle beurt dit weer van die Stoa oorneem. Thomas noem Christus dan ook die Woord of Verbum - dieselfde as die Grieks Logos. Die rationes is woorde (logoi) van die Woord (Logos) in die skepsele.

Teen hierdie agtergrond word Thomas se eksegese van Rom. $2: 14-16$, waar daar gehandel word oor die wet van God wat in die harte van die heidene geskape is, ook duidelik. In God bestaan die lex aeterna. Alle skepsele partisipeer as gevolg van die lex naturalis (die vorme in hulle) egter aan die lex aeterna in God.

Thomas spreek van die similitudines in die skepsele egter alleen as wet (lex) in die geval van redelike skepsele, omdat wet gehoorsaming en dus verstand veronderstel. Dit hang saam met die hiërargiese struktuur wat die syn volgens Thomas openbaar. Bo-aan staan God, wat suiwer vorm is, en heel onderaan materia prima, wat suiwer materie is (en dus nie werklik kan bestaan nie). Daartussen lê 'n hele reeks skepsele wat uit vorm en materie saamgestel is. Die materie vir 'n hoëre ding word die vorm vir die laere ding. Of omgekeerd: die vorm vir 'n laere skepsel is die materie vir' $n$ hoëre. So is die syn volgens Thomas soos 'n piramide met verskillende grade van volmaaktheid opgebou. Die volmaaktheid by 'n skepsel hang af van die mate waarin dit die gelykenis van God vertoon, met ander woorde hoe sterk die goddelike essensie daarin verteenwoordig is. Hoe duideliker die similitudo, hoe hoër staan die skepsel in die synshiërargie en hoe nader aan God. Hoe verder van God, hoe minder goddelik is dit. Daarom maak Thomas duidelik onderskeid tussen die mens wat die beeld (imago) van God vertoon (omdat hy net soos God self oor intellek beskik) en die ander skepsele wat alleen die voetspore (vestigia) van God dra.

Op hierdie stadium sou 'n vergelyking van Thomas se wetsontologie met dié van Plato, die neo-Platonisme en Aristoteles verhelderend kon wees. By die tipering van Thomas se wysgerige konsepsie in die Summa Contra Gentiles is vermeld dat hy 'n Aristotelesinterpretasie toegedaan is. Dit is nader as ' $n$ Platoniserende subsistensieteorie aangedui. In die doctor angelicus se denke is daar dus spore van sowel Aristoteles as 
Plato. Plato self het geen vorm-materieleer gehuldig nie maar slegs die drie ideë (van die ware, skone en goeie) en getalle self as ideale modelle in die intelligibele wêreld geken. Aristoteles het met sy hulemorfisme as't ware Plato se ideë as (wette vorme) in die dinge vermenigvuldig.

Thomas staan ook nie 'n suiwer Aristoteliese wetsidee voor nie maar'n Aristotelesinterpretasie. Die neo-Platoniese wetsidee het intussen ook nog bygekom waarvolgens die Platoniese ideë (vermenigvuldig) in die Gees van God geplaas is. Vergelyk die uiteensetting in verband met Augustinus in die vorige artikel). Die gedagte dat God die wesens van die dinge volgens die exemplares in Homself skep (Thomas) is dus nie 'n Platoniese of Aristoteliese idee nie maar lê nader aan die neo-Platoniesme. Vandaar dat Thomas se konsepsie in die Summa Contra Gentiles ook nie as Platonies aangedui word nie maar as Platoniserend. Die Platoniserende trek kom by Thomas dus veral in sy subsistensieteorie na vore: vanuit die substansie van God kom die subsisterende vorme van die dinge wat ' $n$ assisterende karakter dra.

'n Samevatting van Thomas se plasing van God, wet en kosmos bied dus die volgende beeld. Hy aanvaar een syn wat in 'n transendente (God) en 'n nie-transendente (kosmos) verdeel word. Binne hierdie een syn bestaan die wet sowel in God as in die dinge. Hierdie Ontologie van Thomas is die resultaat van sy sintesedenke waarin hy gepoog het om sowel motiewe uit die Griekse denke as uit die Bybel tot 'n eenheid saam te dink. Op die oog af lyk sy wysgerige Ontologie Skrifmatig. By nadere beskouing blyk egter duidelik die pagane agtergrond.

In die volgende artikel word sy Ontologie nie in detail beskrywe nie maar alleen nog op enkele belangrike uitvloeisels daarvan gewys. Aan die orde kom agtereenvolgens sy leer van die analogia entis, partisipasie, tweeterreineleer en desiderium naturale, mensbeskouing, kenteorie en visie met betrekking tot die verhouding tussen wete en geloof, Filosofie en Teologie.

\author{
B. J. VAN DER WALT \\ P U vir CHO
}


In 'n vorige bydrae in Koers ("Op die spore van Thomas van Aquino: $1274-1974$ " Koers, 40(1): $38-47,1975$ ) is belowe om, in opvolging van die biografiese skets, 'n samevatting van sy filosofiese denkbeelde te gee.

Om ruimte te spaar is verwysings uitgeskakel. Volledige literatuurverwysings word egter gebied in hoofstuk III van my proefskrif Die Natuurlike Teologie met besondere aandag aan die visie daarop by Thomas van Aquino, Johannes Calvyn en die "Synopsis Purioris Theologiae". 2 dele (1974). 